\title{
Functional Outcome after Treatment of Tuberculosis of the Upper Extremity
}

\author{
Ida S. Tacata and Nathaniel S. Orillaza Jr. \\ Section of Hand and Micro Surgery, \\ Department of Orthopedics, College of Medicine and Philippine General Hospital, University of the Philippines Manila
}

\begin{abstract}
Objective. Tuberculosis of the upper extremity, while rare, is still a problem in the Philippines. Included in the primary aim of TB treatment is cure of the patient and restoration of quality of life and productivity. The purpose of this paper is to describe a series of patients treated for Tuberculosis of the upper extremity in the context of level of function and possible factors contributing to disability.
\end{abstract}

Method. Records of the University of the Philippines-Philippine General Hospital Department of Orthopaedics were reviewed to recruit adult patients treated for Tuberculosis of the upper extremity from 2009-2013. Patients who consented were asked to answer a Disability of Arm, Shoulder and Hand questionnaire (DASH) validated for Filipinos.

Results. Fifteen (15) patients presenting with conditions ranging from synovitis to arthritis, treated medically and surgically, were evaluated for function at least 6 months after treatment. The average disability was $23.6 \%$ and, on sub analysis, showed the highest average disability for strenuous activities. Patients reported minimal limitations in doing activities of daily living.

Conclusion. Patients treated for Tuberculosis of the upper extremity still present with relatively low levels of disability. Activities of daily living were generally performed without problems but activities requiring exertion were consistently reported as a difficult task for most participants.

Key Words: tuberculosis, function, upper extremity, surgery

\section{Introduction}

Tuberculosis, while considered rare in developed countries, is still a problem in third world countries. In the Philippines, it was the $6^{\text {th }}$ leading cause of mortality in 2010.

Paper was presented as a poster at the Philippine Orthopedic Association Convention, November 26-29, 2014, Cebu City, Philippines.

Corresponding author: Ida S. Tacata, MD

Section of Hand and Micro Surgery

Department of Orthopedics

Philippine General Hospital

University of the Philippines Manila

Taft Avenue, Ermita, Manila 1000 Philippines

Telephone: +6325548466

Email: istacata@yahoo.com
In three prevalence studies, it was shown to be more prevalent in males in the productive group of the population (25-55) with symptomatic TB reaching up to $18.4 \%$ in 1997 down to only $13.5 \%$ in $2007 .^{1}$

Cases of extrapulmonary Tuberculosis are consistently less common (20-25\%) ${ }^{2-5}$ but more often affects lymphatic, pleural and musculoskeletal system. Mycobacterial infection of the hand and upper extremity are all the more rare, accounting for $10-27 \%$ of skeletal tuberculosis infections. ${ }^{4,5}$ The pathophysiology of Mycobacterial Tuberculosis infection involves destruction of involved tissues via a combination of different mechanisms involving cold abscess formation, caseation necrosis and synovitis. In the later stages, the infection causes chondral destruction and ankylosis. ${ }^{2}$ Due to the variety of involvement, the resulting changes in function also differ for every patient.

Management protocols differ from center to center but in accordance with the basic guidelines set by the World Health Organization (WHO) and the Department of Health $(\mathrm{DOH}) \cdot{ }^{1,2}$

\section{Extrapulmonary Tuberculosis Treatment}

Patients treated for extrapulmonary Tuberculosis follow the chemotherapy protocol as recommended by the WHO which requires patients to be treated with appropriate agents, including Isoniazid (H), Rifampicin (R.), Pyrazinamide (Z), Ethambutol (E) with or without Streptomycin to complete at least 9 months of treatment.

Patients considered treated successfully are those who are either cured (sputum or culture turns negative after treatment) or those who completed treatment. The basis for extrapulmonary Tuberculosis is clinical relying on physical findings with or without ancillary examinations after completion of treatment. ${ }^{1,2}$

\section{Functional Outcome}

Included in the primary aim of TB treatment is the cure of the patient and the restoration of quality of life and productivity. Most efforts at improving outcome, at present, are directed at improving the microbiological management. ${ }^{2}$ While medical cure is rightfully given the most attention, it is also important to assess if the combined modalities of treatment and/or some aspects related to them, have allowed 
the patient to have a better quality of life. Quality of life is probably more noticeable for changes in function of the upper extremity. More recent studies report outcome from the patients' perspective to provide a more realistic picture of the disabilities accounting for specific individual needs and expectations.

\section{Disability of Shoulder and Hand (DASH)}

The DASH is a widely used evaluation tool in evaluating the functional outcome of different conditions of the upper extremity. It is a patient administered questionnaire consisting of 30 basic questions (with additional optional questions, depending on the subject's occupation) aiming to gauge the patient's bimanual ability to perform common activities of daily living and symptoms related to the upper extremity. Based on a standard computation, patient may have a score of 0-100. A higher score equates with worse function or more disability ${ }^{6}$

Estrella et al translated and validated the DASH for the Filipino population in 2013. ${ }^{7}$ The Fil DASH has been used as the standard measurement of general upper extremity in the authors' institution.

\section{Functional Outcome in the Subset}

Several papers have extensively reported on the demographics and treatment protocols of treating extrapulmonary tuberculosis. A few of these focus on the upper extremity but mainly presenting successes in terms of controlling infection. $3,4,8,9,10$ Kotwal in 2009 reported on the improvement of functional outcome of patients treated for tuberculosis of the hand and wrist using Green and O'brien's evaluation tool. ${ }^{11}$

To the authors' knowledge as of the writing of this paper, no local report has been presented on functional outcome of patients treated for TB of the upper extremity. The paucity of available information on the eventual functional outcome of the patients treated for tuberculosis of the limbs leave a lot of unanswered questions in the management and prognostication of these conditions.

This paper aims to present and describe a series of patients treated surgically for TB infection of the upper extremity and look at patterns that may be contributing to the level of disability as measured by DASH.

\section{Methods}

The patients were identified through several entry points:

(1) Out-patient records of the Department of Orthopedics and Department of Medicine Infectious Diseases Section, UP-PGH,

(2) Admissions logbook of the Orthopedic and Medicine Ward, PGH, and

(3) Personal files of the senior authors.
Once identified from the above entry points, the charts, records, and imaging modalities were reviewed.

The following patients were considered for inclusion in the study:

- Adult Filipino patients (18 years old and above) clinically and/or histologically diagnosed with TB of the Upper Extremity, defined as shoulder girdle to the fingertips.

- Treated medically with standard Anti-TB medications for at least 9 months from Jan 2009December 2013

- Treated surgically in the UP-PGH

- With at least 6 months follow-up after completion of treatment

Patients were excluded for the following reasons:

- No consent or unable to answer the DASH. Inability to answer Fil DASH may be due to physical (e.g. poor vision) and/or mental incapacity to read and/or understand the items in the questionnaire.

- Patients with pre-morbid disabilities from other conditions possibly affecting the functions of the limbs through a different disease process (including but not limited to diabetes, muscle dystrophies, previous bone and soft tissue trauma and surgery to the upper extremity, and other arthritides)

Qualified patients were contacted and consented to consult for clinical evaluation by the authors. During the visit, they were instructed to answer the Fil DASH, assisted by the research assistant and investigators.

Results were summarized computing for the average disability as measured by the DASH. Detailed evaluation of the questions items was performed to describe emerging patterns on specific tasks affecting decrease in function of the upper extremity.

\section{Results}

From 2009-2013, 26 patients were surgically managed by the PGH Department of Orthopedics for tuberculous infections of the upper extremity. Of these patients, 5 were reachable but unable to follow-up from the provinces for different reasons. Attempts to conduct the DASH via mail were unsuccessful. Four patients were lost to follow-up and cannot be located with the available information from records and 2 did not complete medical treatment.

Of the 15 patients available for follow-up and evaluation, male to female ratio was $4: 1$, with an average age of 47.9 years old (Range 27-80 years). The average follow-up after surgery was 44.86 months (Range 6-119). Nine patients had pathologies around the wrist, two each in the shoulder, elbow and hand.

The most common presenting problems were arthritis in $60 \%$ of patients and tenosynovitis in $26.67 \%$. Rare 
presentations like osteomyelitis and pyomyositis were also documented in 2 separate patients.

All patients underwent some form of debridement with or without synovectomy. Pancarpal fusion was performed in 2 patients to address severe destruction of the radiocarpal and midcarpal joints and a ray amputation was indicated for deep infection involving the entire index finger in one participant.

The average disability as measured by the DASH was $23.67 \%$ (Range $=0-60.8 \%, \mathrm{SD}=17.2$ ), with 2 patients reporting no disability.

Looking into variables potentially affecting the level of disability, we found that patients presenting with TB of the wrist $(n=9)$ had higher average DASH score (mean=33.6.SD=18.21) compared to affectations in other areas (mean=17, $\mathrm{SD}=12.7$ ). Table 1 summarizes the details of the patients in the series.

Exploring the average ratings per item (scale of 1-5, 5 being the worst), it was shown that recreational activities requiring use of above normal forces showed the highest average item rating in the population (mean=3.41, range 1-5, $\mathrm{SD}=1.4$ ). Patients report minimal to no limitations in doing activities of daily living.

\section{Discussion}

Medical management is still the backbone in the treatment of TB infection. ${ }^{1,2}$ The need for surgery may be viewed through different perspectives. As a prognosticator, it may be a sign of deeper, more difficult problems as it is usually indicated for cases of synovitis, arthritis or severe infection or tissue loss. As a form of preventive measure, it may also be viewed as a possible way to improve function when done early to prevent further complications.

The addition of a surgical procedure is sometimes necessary to decrease the burden on the tissues by different forms of debridement and synovectomy. In some cases, additional procedures that automatically limit the limbs' mobility and/or strength may be required. Amputation may be necessary to adequately remove the diseased parts especially if these become a hindrance if not adequately functioning, as in the case for the index finger of one study subject. Arthrodesis, while also naturally debilitating, is an important procedure to stabilize joints that will predictably cause pain and/or loss of motion after significant destruction of the chondral surfaces. It is interesting to note that the 2 patients who presented with the highest disability scores (50.83\% and $60.83 \%$ ) were the patients who had pancarpal fusion. This is consistent with literature showing an average of $45.6-51.4 \%$ disability for patients having pancarpal fusion for varying indications. ${ }^{12,13}$

Kotwal recognized the need to evaluate the function after treatment of Tuberculosis of the hand using the modified Green and O'Brien. He reported improvement in function after either conservative or medical combined with surgical management in a series of 32 cases. ${ }^{11}$

Similar to earlier reports, patients treated for TB infection of the upper extremity present with some amount of disability, except for 2 patients in this series. This may be

Table 1. Summary of Patients Profiles and DASH Scores

\begin{tabular}{|c|c|c|c|c|c|c|c|}
\hline Patient & Age & Sex & Diagnosis & $\begin{array}{l}\text { Body Part } \\
\text { Involved }\end{array}$ & Surgical Procedure & $\begin{array}{c}\text { DASH Score } \\
\text { (Percent Disability) }\end{array}$ & Follow-up \\
\hline 1 & 35 & M & $\begin{array}{l}\text { TB osteomyelitis head of proximal } \\
\text { phalanx, middle finger, } \mathrm{R}\end{array}$ & Hand & Debridement, curettage & 4.17 & 6 \\
\hline 2 & 27 & $\mathrm{~F}$ & TB arthritis, wrist, $\mathrm{R}$ & Wrist & Arthrotomy, synovectomy & 19.17 & 32 \\
\hline 3 & 43 & $\mathrm{~F}$ & $\begin{array}{l}\text { Chronic TB dactylitis with burnt out } \\
\text { arthritis, metacarpophalangeal joint, } \\
\text { index finger, L }\end{array}$ & Hand & Ray amputation & 36.67 & 22 \\
\hline 4 & 87 & M & TB arthritis, wrist, L & Wrist & Arthrotomy, synovectomy & 40 & 9 \\
\hline 5 & 30 & M & $\begin{array}{l}\text { TB arthritis pyomyositis, } \\
\text { shoulder/arm with pathologic } \\
\text { shoulder dislocation, } \mathrm{R}\end{array}$ & Shoulder & $\begin{array}{l}\text { Debridement, drainage, } \\
\text { arthrotomy, open reduction }\end{array}$ & 27.50 & 14 \\
\hline 6 & 33 & M & TB flexor tenosynovitis wrist, $\mathrm{L}$ & Wrist & Debridement, synovectomy & 22.50 & 29 \\
\hline 7 & 57 & M & TB arthritis, wrist, L & Wrist & $\begin{array}{l}\text { Debridement, synovectomy, } \\
\text { pancarpal fusion, wrist }\end{array}$ & 60.83 & 76 \\
\hline 8 & 56 & $\mathrm{~F}$ & TB arthritis, wrist, $\mathrm{R}$ & Wrist & $\begin{array}{l}\text { Debridement, synovectomy, } \\
\text { pancarpal fusion }\end{array}$ & 50.83 & 82 \\
\hline 9 & 36 & M & TB extensor tenosynovitis, wrist, $\mathrm{R}$ & Wrist & Debridement, synovectomy & 12.50 & 8 \\
\hline 10 & 32 & M & TB arthritis, elbow, $\mathrm{R}$ & Elbow & Debridement & 0 & 16 \\
\hline 11 & 42 & M & $\begin{array}{l}\text { TB arthritis with extensor } \\
\text { tenosynovitis wrist, L }\end{array}$ & Wrist & $\begin{array}{l}\text { Debridement, arthrotomy, } \\
\text { synovectomy }\end{array}$ & 10.83 & 88 \\
\hline 12 & 63 & M & TB arthritis, shoulder, L & Shoulder & Debridement, arthrotomy & 30 & 23 \\
\hline 13 & 36 & M & TB synovitis, wrist, $\mathrm{R}$ & Wrist & $\begin{array}{l}\text { Debridement, arthrotomy, } \\
\text { synovectomy }\end{array}$ & 20 & 82 \\
\hline 14 & 80 & M & $\begin{array}{l}\text { TB flexor tenosynovitis, thumb and } \\
\text { wrist L }\end{array}$ & Wrist & $\begin{array}{l}\text { Debridement, flexor } \\
\text { synovectomy }\end{array}$ & 0 & 119 \\
\hline 15 & 62 & M & TB arthritis, elbow, R & Elbow & Debridement arthrotomy & 20 & 67 \\
\hline
\end{tabular}


due to the fact that TB can cause significant destruction of bone and soft tissue especially because of its usually chronic course and often tolerable initial symptoms.

This series of surgically treated patients presented at various stages of involvement and with varying indications for surgical intervention. In spite of this, the average disability after treatment, as a group, was relatively low. The average disability of $23.67 \%$ is not that far from normative values computed from 1706 normal participants of $10.10 \%$ (SD 14.68). ${ }^{14}$

Looking into the details of the items in the questionnaire allowed an in-depth evaluation of which aspects of upper extremity function were more affected by the disease. Having these details may aid in the counselling of patients on which aspects of function are more likely to be impaired even after treatment. On the positive side, activities of daily living are usually performed with minimal problems for most of the patients.

We have shown that patients operated on for TB infection of the upper extremity generally function well, mostly unhappy with activities requiring exertion or lifting with the involved upper limb but able to perform activities of daily living.

Because of the rarity of the condition, it was difficult to collect enough patients to achieve power for statistical analysis. This initial report is limited to the series of patients available for follow-up from a single institution. As a continuing project, this is intended to be a multicentre study to collect enough patients to determine prognostic factors for disability using multiple regression analysis.

\section{References}

1. Department of Health. Manual of Procedures of the National Tuberculosis Control Program 5th ed. [Online]. 2014 [cited 2015 March]. Available from http://www.doh.gov.ph/sites/default/files/NTCPMOP.pdf.

2. World Health Organization. Guidelines for Treatment of Tuberculosis, $4^{\text {th }}$ ed. [Online]. 2010 [cited 2015 Jan]. Available from http://www.who.int/tb/publications/2010/9789241547833/en/.

3. Al-Qattan MM, Al-Namla A, Al-Thunayan A, Al-Omawi M. Tuberculosis of the hand. J Hand Surg Am. 2011; 36(8):1413-21.

4. Martini M, Benkeddache Y, Medjani Y, Gottesman H. Tuberculosis of the upper limb joints. Int Orthop. 1986; 10(1):17-23.

5. Benkeddache $Y$, Gottesman H.Skeletal tuberculosis of the wrist and hand: a study of 27 cases. J Hand Surg Am. 1982; 7(6):593-600.

6. Institute for Work and Health. Scoring the DASH [Online]. 2006 [cited 2015 Jan]. Available from http://dash.iwh.on.ca/system/files/ dash_scoring_2010.pdf.

7. Estrella EP, Orillaza NS, Reyes RR, Tabladillo S.Translation and Validation of the Disability of Arm, Shoulder and Hand (DASH) in the Filipino Population. Presented as a poster in the Philippine Orthopedic Association Annual Meeting, Nov 2014.

8. American Thoracic Society, CDC, Infectious Diseases Society of America. Treatment of tuberculosis. Morbidity and Mortality Weekly Report: Recommendations and Reports, 2003, 52(RR-11):1-77.

9. Visuthikosol V, Kruavit A, Nitiyanant P, Siriwongpairat P. Tuberculous infection of the hand and wrist. Ann Plast Surg. 1996; 37(1):55-9.

10. Skoll PJ, Hudson DA. Tuberculosis of the upper extremity. Ann Plast Surg. 1999; 43:374-8.
11. Kotwal PP, Khan SA. Tuberculosis of the hand. Clinical presentation and functional outcome in 32 patients. J Bone Joint Surg. 2009; 91(8):1054-7.

12. Sauerbier M, Kluge S, Bickert B, Germann G. Subjective and objective outcomes after total wrist arthrodesis in patients with radiocarpal arthrosis or Kienböck's disease. Chir Main. 2000; 19(4):223-31.

13. Kalb K, Ludwig A, Tauscher A, Landsleitner B, Wiemer P, Krimmer H. Treatment outcome after surgical arthrodesis. Handchir Mikrochir Plast Chir. 1999; 31(4):253-9.

14. Hunsaker FG, Cioffi DA, Amadio PC, Wright JG, Caughlin B. The American academy of orthopaedic surgeons outcomes instruments: normative values from the general population. J Bone Joint Surg Am. 2002; 84-A(2):208-15. 